\title{
Information for Disaster Preparedness: A Social Network Approach to Rainwater Harvesting Technology Dissemination
}

\author{
Subhajyoti Samaddar • Makoto Murase • \\ Norio Okada
}

Published online: 3 June 2014

(C) The Author(s) 2014. This article is published with open access at Springerlink.com

\begin{abstract}
Rainwater harvesting technology is considered an innovative and effective mechanism for reducing drinking water risks due to arsenic contamination and water salinity in coastal Bangladesh. However, adoption of such tanks remains elusive. Most studies on disaster risk communication are predominantly based on individuallevel cognitive modeling approaches, which fail to address the role of social groups, human relations, and other collective social factors in the dissemination process of disaster preventive measures. From the viewpoint of social implementation, community adoption of unfamiliar technology for disaster risk mitigation and preparedness requires another approach. Given the challenge to promote rainwater harvesting technology in the study area of coastal Bangladesh, this study examines the role of various social networks including cohesive groups (friends), structural equivalent groups (individuals who have the same position in society), and spatial groups (neighbors) in three information sharing and processing activities-hearing, observation, and discussion. Results show that those individuals who have similar cohesive affiliations tend to become hearing and discussion partners. Cohesive groups share a learning opportunity and are bounded by normative
\end{abstract}

S. Samaddar $(\bowtie)$

Disaster Prevention Research Institute, Kyoto University, Gokasho, Uji, Kyoto 6110011, Japan

e-mail: samaddar14@gmail.com

M. Murase

Institute for Sky Water Harvesting, 1201-2 Fukasawa, Gotemba City, Shizuoka Prefecture 4120023, Japan

N. Okada

Institute for the Research of Disaster Area Reconstruction, Kwansei Gakuin University, Hyogo 6628501, Japan constraints in terms of direct and intimate social relations. Spatial groups facilitate observation, which provides visual learning. Structurally equivalent groups are not relevant in adoption dissemination; therefore competition or similar social environment did not influence the rainwater tank dissemination activities.

Keywords Bangladesh - Drinking water risks · Rainwater harvesting - Social networks - Water salinity

\section{Introduction and Background}

Dwellers in coastal areas of Bangladesh are at risk due to the salinity of drinking water and arsenic contamination of groundwater, both of which are considered direct and indirect impacts of climate change. A conservative estimation by the Ministry of Environment and Forest (MOEF 2006) reveals that more than 20 million people living along the coast are affected by varying degrees of salinity in their drinking water. The most severely affected districts are Patuakhali, Pirojpur, Barguna, Satkhira, Bagerhat, and Khulna in southern Bangladesh where salinity intrusion has risen by $45 \%$ in the last five decades (IRIN 2007). Reports indicate that saltwater from the Bay of Bengal has infiltrated more than $100 \mathrm{~km}$ inland along tributary channels and that infiltration is causing a huge crisis in the provision of adequate fresh drinking water supplies (Allison et al. 2003). Factors identified as causing increased water salinity in coastal Bangladesh are mainly climate change impacts such as sea-level rise, abnormal high tides, and storm surges (Khan et al. 2011). Based on historical data from three coastal stations, sea level has risen over the last 22 years in Bangladesh to a much higher degree than the global average over 100 years (MOEF 2006). An $\sim 5 \mathrm{~mm}$ 
rise in sea level per year was reported in coastal Bangladesh (MOEF 2006). Salinity intrusion is likely to increase in the future because of further reduced river flows, increased upstream withdrawals, longer-term climate change that may decrease dry season rainfall, and increased sea-level rise (Khan et al. 2011).

Among the direct man-made factors affecting salinity levels, shrimp farming is considered one of the major reasons behind increasing water salinity. Shrimp farmers in Bangladesh mainly cultivate Indian Tiger Shrimp (Peneaus monodon), a species that cannot be cultivated in fresh water (Sarwar 2005). Thus many coastal areas have been converted to saline water fields over the last two decades. One estimate shows that the number of shrimp farms increased 87 times between 1975 and 2004 (Sarwar 2005). Increased unavailability of fresh water will force people to drink contaminated high-salinity water, leading to increases in cholera, diarrhea, hypertension, premature delivery, skin disease, acute respiratory infection, and other waterborne diseases (Haque 2006; Khan et al. 2011).

Along with water salinity, the growing concern in coastal and other parts of Bangladesh is arsenic contamination of drinking water. During the late 1970s, the Bangladesh Government supported by the United Nations Children's Fund (UNICEF) initiated a mass project installing shallow tube-wells (STWs) to provide safe drinking water to the rural population suffering from a number of water-borne diseases such as diarrhea and cholera due to the contamination of drinkable surface water by microorganisms (fecal bacteria) (Alam et al. 2002; Ahmed et al. 2006). This nationwide project, known as the groundwater revolution, saved millions of lives as mortality and morbidity rates attributed to the stated waterborne diseases were significantly reduced (Alam et al. 2002; Khan and Yang 2013). By the 1990s, the provision of STWs reached about $80 \%$ of the rural population but it was discovered that these STWs were contaminated with derived geological arsenic (Alam et al. 2002). Arsenic is mostly found in withered aquifers, those at the depth of less than $150 \mathrm{~m}$. These STWs consist of tubes that are of $5 \mathrm{~cm}$ in diameter and are inserted into the ground at a depth of usually less than $200 \mathrm{~m}$ (Alam et al. 2002). Arsenic can occur in groundwater naturally without an anthropogenic source. There is a general consensus among scientists that arsenic release into the groundwater of the Bengal Basin is facilitated by microbial metabolism of organic matter contained in flooded river plain and delta deposits (Ahmed et al. 2006). Some researchers reported that groundwater contamination by arsenic is attributed to activities that are mediums to anthropogenic sources such as excessive use of pesticides and fertilizers (for example the use of phosphate fertilizer) that change the composition of groundwater (Anawar et al. 2002; Ahmed et al. 2006; Mosler et al.
2010). Excessive withdrawal of groundwater for irrigation during the dry season causes a marked fluctuation of water table. During such fluctuation, decomposition of pyrite occurs as groundwater is aerated and acid released due to this decomposition leaches arsenic from pyrites (Alam et al. 2002).

Human exposure to arsenic can occur both directly and indirectly (Khan and Yang 2013). Inhabitants in Bangladesh primarily are directly exposed to arsenic through the consumption of arsenic-contaminated groundwater from STWs (Smith et al. 2000). The magnitude of the health risk depends on arsenic specification, duration and frequency of exposure, and demographic factors (Anawar et al. 2002; Khan and Yang 2013). The health problems that arise as a result of ingesting arsenic-contaminated drinking groundwater take time, generally $10-15$ years, to occur (Alam et al. 2002). For this reason, the actual extent of the contamination and the number of people with skin disease caused by arsenic might be higher than the current estimation (Smith et al. 2000). The health problems of excessive arsenic intake are diverse and known as Arsenicosis (Mosler et al. 2010). Arsenic poisoning is manifested primarily in skin lesions on the palms of the hands and soles of the feet; chronic exposure can cause adverse health effects including skin and lung cancers (Hopenhayn-Rich et al. 1998). Nationwide, 1.2 million people already have identifiable symptoms of Arsenicosis (Karim 2000). Recent studies show that approximately 30-40 million people are at risk of drinking arsenic contaminated groundwater above the national guideline of $50 \mathrm{ppb}$ (parts per billion) or $0.05 \mathrm{mg} \mathrm{l}^{-1}$ (Ahmed et al. 2006; Khan and Yang 2013). The number of people drinking arsenic contaminated groundwater would be much higher when applying the World Health Organization (WHO) guideline of $10 \mathrm{ppb}$ or $0.01 \mathrm{mg}^{-1}$ (Smith et al. 2000; Khan and Yang 2013). Arsenic contamination in Bangladesh is recognized as a major public health emergency and preventing arsenic exposure by supplying safe water is thus an important policy goal.

Considering the severity of risks to drinking water in Bangladesh, many nonstructural measures and adoption of preventive technology by households are strongly recommended for risk reduction. Rainwater harvesting is considered one such innovative prevention mechanism that could be adopted by households to reduce drinking water risks (Samaddar and Okada 2008). However, studies across Bangladesh have reported that even after spending lots of money and undertaking many public awareness and education programs, the adoption of preventive measures remains elusive (Smith et al. 2000; Hadi 2003). Several factors contribute to low preparedness and adoption rates, such as the habits and attitudes of individuals (Hadi 2003), lack of public awareness (Jakariya et al. 2003), existing 
poverty, distrust of government agencies and nongovernment organizations (NGOs) (Smith et al. 2000), lack of education, and poor risk communication mechanisms (Hoque et al. 2004). Akmam and Higano (2007) reported that in many cases different government and nongovernment organizations suggest that local communities adopt various technologies for getting safe water, free from arsenic and salinity contamination. But the results from tests conducted on different technologies are sometimes contradictory (Hoque et al. 2004), and the local communities are confused as to how to select the most appropriate technology. Therefore, the challenge of how best to communicate with the end users of water harvesting systems and to disseminate the technology amongst the general population remains.

Many studies have attempted to understand household disaster preparedness behavior. Most researchers use heuristic models to explain the interactive outcome of numerous cognitive variables in household decision making, such as risk perception, self-efficacy, outcome expectancy, implementation, and cost (Duval and Mulilis 1999; Lindell and Whitney 2000; Grothmann and Reusswig 2006; Paton et al. 2006; Martin et al. 2007; Tekeli-Yeşil et al. 2010). Heuristic and cognitive preparedness behavior models consider an individual's decision-making process as an isolated event, one in which individuals collect and process information to develop decisions as "atomized units connected to a social system" (Scherer and Cho 2003). However, these models do not consider how information is shared among individuals and meanings are socially constructed. Empirical observation suggests that individuals make decisions not in social isolation, but in interaction with others (Behrman et al. 2002). Social intimacy, frequent interaction, and social norms all create shared contexts for information sharing and can be used to interpret prior behaviors and attitudes that influence subsequent attitudes and behaviors (Dean and Brass 1985). Hence, social implementation of innovative technology lies to a great extent in the understanding of social networks and its role in information-processing activities (Granovetter 1983; Rogers 1983). Studies using this line of pursuit in disaster and other forms of risk management are rare (Scherer and Cho 2003; Brenkert-Smith et al. 2013). This study explores the role and nature of social networks in the information sharing and processing activities of individuals in the dissemination of rainwater harvesting technology in coastal Bangladesh.

\subsection{Role of Social Networks in Disaster Prevention Technology Dissemination}

Social network theory argues that the implementation of innovative technology, such as disaster prevention technology, to a great extent lies in understanding social networks and their role in information processing activities (Granovetter 1983; Rogers 1983). This theory postulates that in the dissemination process of innovative technology, individuals observe the behaviors of others, learn from their experiences through social interactions, and then make appropriate decisions based on their subjective reality (Coleman et al. 1957; Granovetter 1978; Valente 1995). Becker (1970). This suggests that to make or develop decision, particularly to adopt decisions around new technologies, social networks help an individual by providing information about the innovation that otherwise an individual might have missed; creating social influence on an individual to accept or reject the innovation; and supplying social support to an individual to implement the decision and thus to legitimize the innovation. Social networks not only provide opportunities for receiving additional knowledge, but they also impose constraints on the behavior of many who might otherwise wish to adopt the knowledge. Understanding the structure of social networks and their roles in information processing activities are critical to understanding any innovative technology dissemination (Granovetter 1978; Rogers 1983).

Studies in disaster preventive knowledge and technology dissemination have shown that several uncertainties, such as the advantages and disadvantages of the prescribed measures, social acceptance of technology and the socioeconomic cost of implementation, made adoption very risky and often discouraged individuals (Lindell and Whitney 2000; Terpstra 2011; Samaddar et al. 2012). Diffusion of innovation studies argue that in order to reduce such uncertainties, potential adopters seek more comprehensive and reliable information about the innovative technology or practice in question (Valente 1995). From this perspective, a comprehensive knowledge about the hardware and software of the innovation is critical for a potential adopter to make decisions (Rogers 1983). Hardware comprises of shape, size, structure, and other engineering aspects. Software refers to function, utility, effectiveness, and operational system of the technology. To acquire comprehensive and personal knowledge, individuals engage in three critical information sharing activities: hearing, observation, and discussion. Hearing, a two-way communication process, allows an individual to learn about the software components of innovation. Observation is a one-way communication process, which allows an individual to learn about the hardware components of the technology. Individuals who have the opportunity to engage in both these information sharing activities (hearing and observation) are able to acquire more comprehensive knowledge than those who have an opportunity to participate in only one or none of the information sharing activities. 
Apart from hearing and observation, discussion is also an important activity in developing comprehensive knowledge. The adoption of innovative technology is not an instantaneous process. Individuals do not make decisions immediately after introduction to the technology, but in the persuasion and decision stages individuals may seek advice and personal experiences from other sources in order to make a prudent decision (Rogers 1983). Such discussions with others also influence an individual's adoption behavior.

On whom do individuals depend to acquire information? Generally mass media do not provide an effective medium for technology dissemination, particularly in small towns and rural areas (Katz 1957; Lin and Burt 1975; Valente 1995). Individuals depend on interpersonal channels or social networks to acquire information because social networks provide support and confidence in the suggested technology (Behrman et al. 2002) and they help the potential adopters to manage personal needs and tackle situation specific questions (Schramm 1973). Individuals may depend on a range of other individuals or network partners to obtain various kinds of information, because information sharing amongst individuals is constrained by trust, confidence, and similarities in experience between the actors (Coleman et al. 1957; Shah 1998; Paton 2008). Therefore, in the diffusion of disaster prevention technology, selecting appropriate social referents for each type of information is integral to successfully influencing the potential decision maker to adopt the technology.

\subsection{Social Networks and Information Sources}

Social network studies have found that individuals are influenced by many actors in the social system or network. For example, Coleman et al. (1957) and Menzel and Katz (1955) found cohesive groups exhibit greater behavioral conformity, whereas Burt (1987) found that an individual's decision-making process is influenced by those having structurally similar positions. Conversely, Granovetter (1983) showed that weaker social ties are more important to getting information, whereas Valente (1996) argued individuals follow others with whom he or she has direct and strong social relations. Therefore, individual social referents in respect of acquiring information have yet to be clearly defined. Based on the social network theory, we examine three social network groups to seek information and process activities.

\subsubsection{Cohesive Group or Network}

The composition of a cohesive group is determined by the degree of interpersonal contacts or ties of its members. An
System Social Network $-\mathrm{X}$

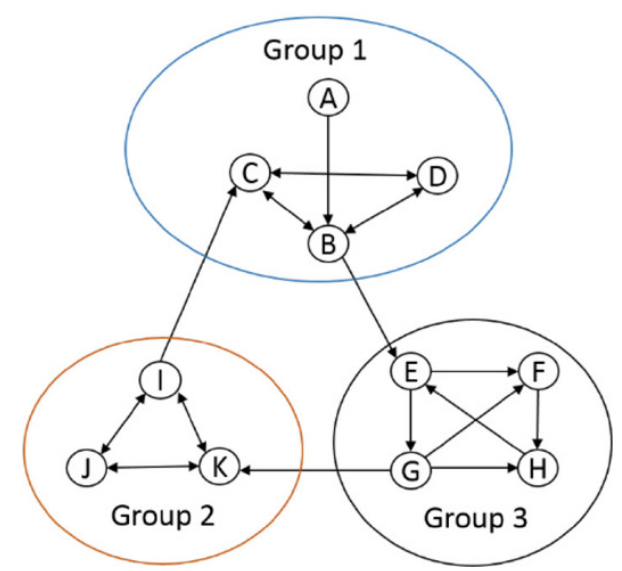

Fig. 1 Categorization of groups based on cohesion in a social network

individual may have various direct and indirect social ties with others in a network or in a community, but his or her cohesive group will be comprised of those with whom he/ she has the highest social interaction. The graphical representation in Fig. 1 shows that there are 11 individuals in social network X. Based on the degree of connectedness, individuals are separated into three groups. In each group, it is not necessary for all members to have direct contact with each other, but an individual belongs to that group in which he/she has the higher number of social ties. For example, Actor $\mathrm{G}$ has direct contact with Actor K, but they belong to different groups because Actor $G$ has three connections with the members of Group 3, but only one connection with Group 2. The same rule also applies to all actors in the system.

Several social network studies have found that frequency, intensity, and proximity of interaction among cohesive members foster more intense information sharing than amongst non-cohesive members (Ibarra and Andrews 1993). If a member of a cohesive group learns about an innovation, this information may quickly pass to the other members of that cohesive group as the members of a cohesive group enjoy a higher degree of connectivity (Coleman et al. 1957; Ibarra and Andrews 1993; Scherer and Cho 2003). In contrast, Granovetter (1983) argues that cohesive groups prohibit the infiltration of new ideas and only provide redundant information. Studies on social networks and their role in innovative technology dissemination are very rare in the context of Bangladesh, yet a study by Gayen and Raeside (2010) on contraceptive practice of women confirmed that cohesive group partners or strong social networks played a significant role to obtain new ideas and put social pressure, both negative and positive, on innovation adoption decision. 
System Social Network - Y

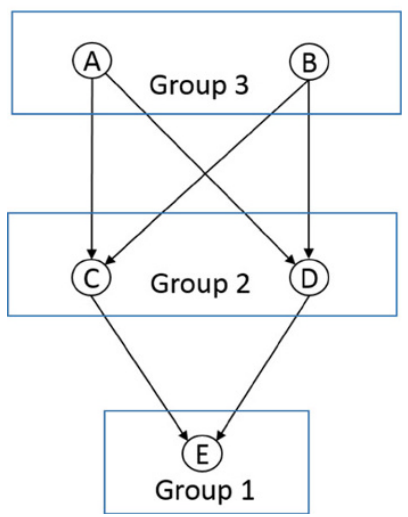

Fig. 2 Structural equivalent groups in a social network

\subsubsection{Structural Equivalent Group}

Structural equivalent actors are those who share a similar pattern of relationships (to and from) with others, thus occupy the same position in a network. Consider the example in Fig. 2, on the law of structural equivalence, 5 actors in social network Group "Y" have been divided into three groups. In this graph Actors $\mathrm{C}$ and $\mathrm{D}$ are structurally equivalent since both are linked to actor $\mathrm{E}$ and both have ties with Actors $\mathrm{A}$ and B. In addition, Actors A and B are structurally equivalent because both also have ties to $C$ and $D$. Structurally equivalent actors are subsets and representing them together as a single structural entity is called an equivalence class or position. Actors of a structurally equally positioned group or class may or may not have direct ties with each other.

Structural equivalence theory presumes that people are influenced by others with whom they share similar position in the network. Social environment, competition, and socialization process are all defined under the structural equivalence theory. Burt (1987) showed that competition exists between two actors who share a similar position in the social network and competition favors adoption. Research has shown that indirect relations are part of a social environment that provides similar opportunities and constraints to the individuals belonging to the same position in a society or community (Marsden and Friedkin 1994). Structurally equivalent actors may not directly influence each other, but sharing a similar social environment and socialization process may cause indirect influence (Burt 1987).

\subsubsection{Spatial Group}

The behavioral similarities of individuals can be identified by geographical proximity. People who live within a similar geographical boundary or territory share common values and emotions and thus geographical proximity affects the social contagion process (Rogers 1983). Physical proximity allows individuals to make observations, learn about other experiences, and share ideas and values with each other. These interactions help an individual to become aware of an innovation and/or to reduce risk by witnessing the consequences of adoption, and the adoptive behavior of neighborhood peers creates social pressure on neighboring individuals (Samaddar and Okada 2007). Individuals who live in the same neighborhood have generally greater social interaction and their adoption behavior is channelized through social learning and social influence generated due to neighborhood membership (Rogers 1983).

\subsubsection{Socioeconomic Characteristics}

Diffusion of innovation and information-sharing activities are subjected to adopters' characteristics (Becker 1970; Rogers 1983). Socioeconomic characteristics such as age, educational attainment, economic wellbeing, religion, and cosmopolitanism create constraints and opportunity for access to information and also influence their adoption behavior (Lindell and Whitney 2000). The manner and extent to which information sharing happens between individuals also depend on socioeconomic affiliation and attachment. Therefore we also examine the adopters' socioeconomic characteristics in relation to information processing activities.

\subsection{Aim and Objectives}

This study investigates how social network groups influence and constrain individuals seeking information and processing activities in water harvesting technology dissemination in coastal Bangladesh. The following objectives are addressed in this study:

- Examine the pattern of three critical information processing activities-hearing, observation, and discussion-in the water harvesting dissemination process.

- Investigate the comparative roles and influences of various social network groups including cohesive groups (friends-learning and influence), structural equivalent groups (those who share similar role and position in society/community-competition and socialization), and spatial groups (neighbors) and socio-cultural groups on three information processing activities.

\section{Case Study: Rainwater Harvesting Innovation and Dissemination in Morrelganj Municipality, Coastal Bangladesh}

This study examines the rainwater harvesting technology dissemination in a small municipality in coastal 


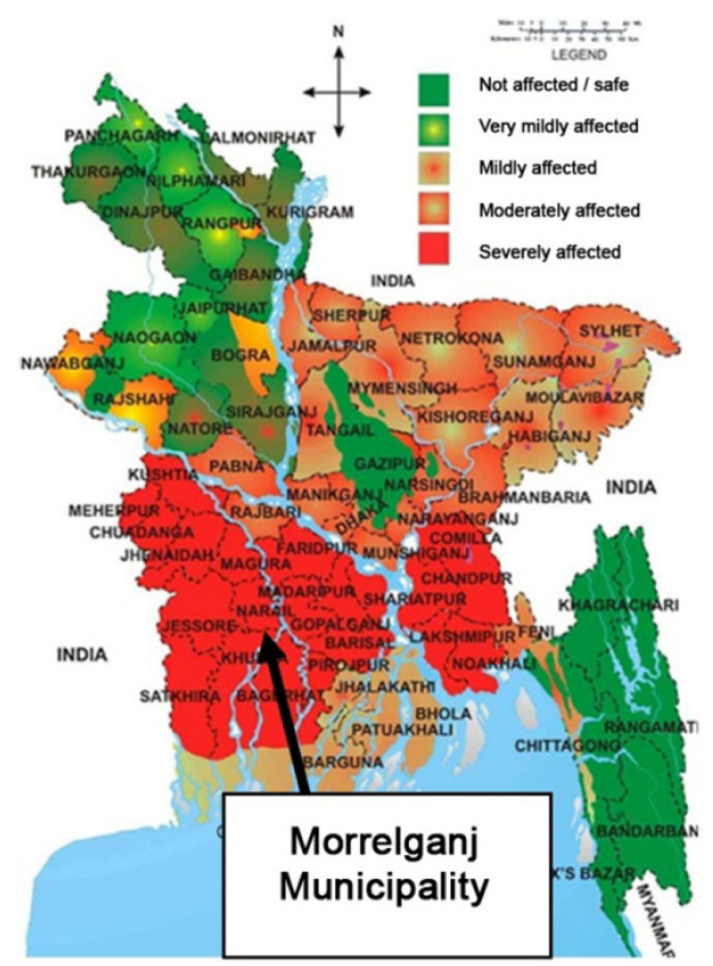

Fig. 3 Arsenic contaminated districts of Bangladesh and location of Morrelganj. Source SOESJU (2004)

Bangladesh, called Morrelganj (Fig. 3). Due to arsenic contamination of groundwater and water salinity, thousands of people in Morrelganj and its surrounding areas suffer from acute drinking water pollution. In 2003, 58 tube wells in the Morrelganj Municipality were arsenic contaminated (Morrelganj Upazila Karjalay 2003). Apart from the arsenic contamination of groundwater, salinity intrusion due to sea-level rise has brought the local community under severe threat of drinking water risks. Considering the urgent need of potable water supply, a rainwater harvesting system at the household level was initiated by a Japan based NGO called People for Rainwater Utilization (PR) in collaboration with a few local NGOs. The idea of the rainwater harvesting initiative is to collect the rainwater from residential building roof tops during the rainy season and preserve it in a ring-tank that is protected from air and light (Fig. 4) for drinking water purpose in dry season. The capacity of each rainwater tank is 4,500 liters, which is considered enough to preserve rainwater needed for an entire dry season for a family having up to 6-7 members. The cost of a rainwater tank is $15,000-20,000$ Taka (USD 190-260). To promote this innovative mechanism for providing potable water, several awareness programs were undertaken by the local NGOs. These included door-todoor campaigns by NGO members, poster and banner displays, and formation of neighborhood committees to raise drinking water pollution awareness. Since 2004, a

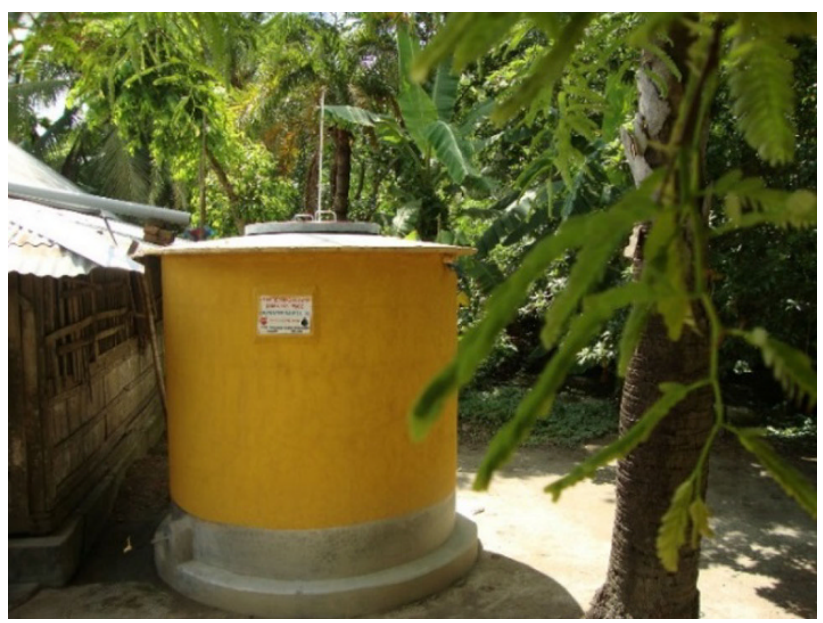

Fig. 4 Rainwater harvesting tank $(4,5001)$ for reducing drinking water risks, Morrelganj, Bangladesh. Photograph by S. Samaddar, August 2012

total of 68 tanks have been installed in Morrelganj Municipality. Since then Morrelganj Municipality has become an epicenter of this movement and hundreds of more tanks have been installed in surrounding rural areas.

The study area of Morrelganj Municipality is like an overgrown village under the jurisdiction of Bagerhat district. The population of Morrelganj earns their livelihood mainly from small trading, business, government service, agriculture, and fishing (Morrelganj Municipality 2002). Muslims are the numerically dominant ethnic and religious group in the region, although there are also a small number of Hindus (Morrelganj Upazila Karjalay 2003). In the present study context, it is important to note that though the municipality is divided into nine administrative jurisdictions, called wards. Municipality settlements are socially and spatially more distinctive in Para or neighborhoods. Each Para contains a homogeneous group of individuals who share a strong sense of belonging based on religion, kinship ties, and occupation. These shared characteristics separate one group of individuals from another. Each Para is occupied by a particular community. For example, the inhabitants of Serestadarbari are Hindus; Kuthibari is mainly occupied by school teachers; Bazarpara is a market place, mostly occupied by businessmen. The attitude and behavior of individuals are controlled and governed by the Para to a great extent.

\section{Survey Design, Data Collection, and Methods of Analysis}

Our target respondents were all 68 tank adopters in Morrelganj Municipality. However, we were able to conduct 
the survey among only 56 rainwater harvesting tank owners. Of the 12 non-interviewed tank adopters, five were NGO workers who were deliberately excluded from the survey population. The other seven tank owners were not available for interviews despite more than three visits by project interviewers. Out of the 56 interviewed tank owners, seven were dropped from the analysis because of incomplete responses. Finally, 49 tank owners were considered for the analysis. The heads of the households, who are the main household decision makers, were chosen for interviews except in three cases where female respondents were interviewed because they took the main initiative in learning about rainwater harvesting and made the final decision to install rainwater tanks. We conducted structured, face-to-face interviews at the home of each respondent so that respondents could express themselves freely. This practice also helped other members of the households to express their views, which provided us with additional information that was overlooked or could not be recalled by the key informants. Focusing on the study objectives, we collected the following data:

(1) Sources of information were collected by asking the adopters to identify where they first learned about the rainwater tank. Two broad source categories were identified: mass media including radio, TV, newspaper, and the internet; and interpersonal contacts including friends, relatives, co-workers, neighbors, and acquaintances who were NGO workers.

(2) Dividing the information seeking activities into three types, social network dominated information-seeking activities were identified by asking the respondents the following three survey questions:

- Social Networks of Hearing: "Kindly name three persons from whom you first heard about the rainwater tank";

- Social Networks of Observation: "Can you remember where you first observed the rainwater tank? If yes, kindly name three places or houses of tank owners where you first observed the rainwater tank";

- Social Networks of Discussion: "Kindly name three persons with whom you discussed or from whom you took suggestions and advice before your tank installation."

Matrixes were formed for each social network in such a way that cell entry $X_{i j}$ equaled one if actor $i$ selected actor $j$ for a particular interaction. For example, if actor $i$ heard about the tank from actor $j$, the cell entries equaled one, and all other entries equaled zero.

(3) For data on general interpersonal contacts and social groups, apart from the above three sociometric question items, we collected sociometric data on adopters' personal interaction in day-to-day life. For this, respondents were asked: "Kindly name three tank adopters in your municipality with whom you most often interact, meet, and share spare time in your daily life." These sociometric data (Fig. 5) were used to group the adopters into structurally equivalent groups and also into cohesive groups. To construct spatial adopter groups, we used adopters' neighborhood affiliation records, and a neighborhood affiliation matrix was formed accordingly.

(4) Characteristics of adopters were identified under four broad sections of survey items including sociodemographic attributes, economic condition, and the location of their houses or the name of the neighborhood they live. Sociodemographic characteristics and economic conditions of adopters are summarized in Table 1.

A number of analytical techniques were used in the present study. Each technique is described briefly below.

(1) Structural equivalent groups: We determined structural equivalence using a block modeling procedure CONCOR (convergence of iterated correlations) in UCINET Social Network Software 6.0 Version 1.00 (Borgatti et al. 2002). This positional clustering technique identifies groups of actor with relationships that are similar in terms of correlations between ties and divides them into blocks. We determined structural equivalence using the sociometric data of adopters on personal interaction in day-to-day life. We have determined the number of partitions by analyzing intra- and interblock tie correlations. Structurally equivalent blocks should exhibit highly correlated patterns of relationships within themselves and minimal correlations should exist with external actors. We divided the networks into 8 structural equivalent groups (Fig. 6).

(2) Cohesive group: The cohesive group was determined by using the "FACTIONS" technique by running UCINET Social Network Software 6.0 Version 1.00 (Borgatti et al. 2002). The FACTIONS routine in UCINET takes the bipartite graph as input and uses a combinatorial optimization algorithm called Tabu Search (Glover 1989) to assign nodes to as many clusters as hypothesized by the user (researcher) so as to maximize a fit criterion. The fit criterion is a correlation between the observed data and an idealized pattern in which the density of ties within groups is $100 \%$ and the density of ties between groups is $0 \%$ (Borgatti and Everett 1997). We determined cohesive group by using the sociometric data of adopters on personal interaction in day-to-day life as 
Fig. 5 Interpersonal contacts or social networks of rainwater tank adopters in Morrelganj $(n=49)$. Survey Question:

"Kindly name three tank adopters in your municipality with whom you most often interact, meet, and share spare time in your daily life." The figure is not drawn to scale. Location of the nodes (actors) is random

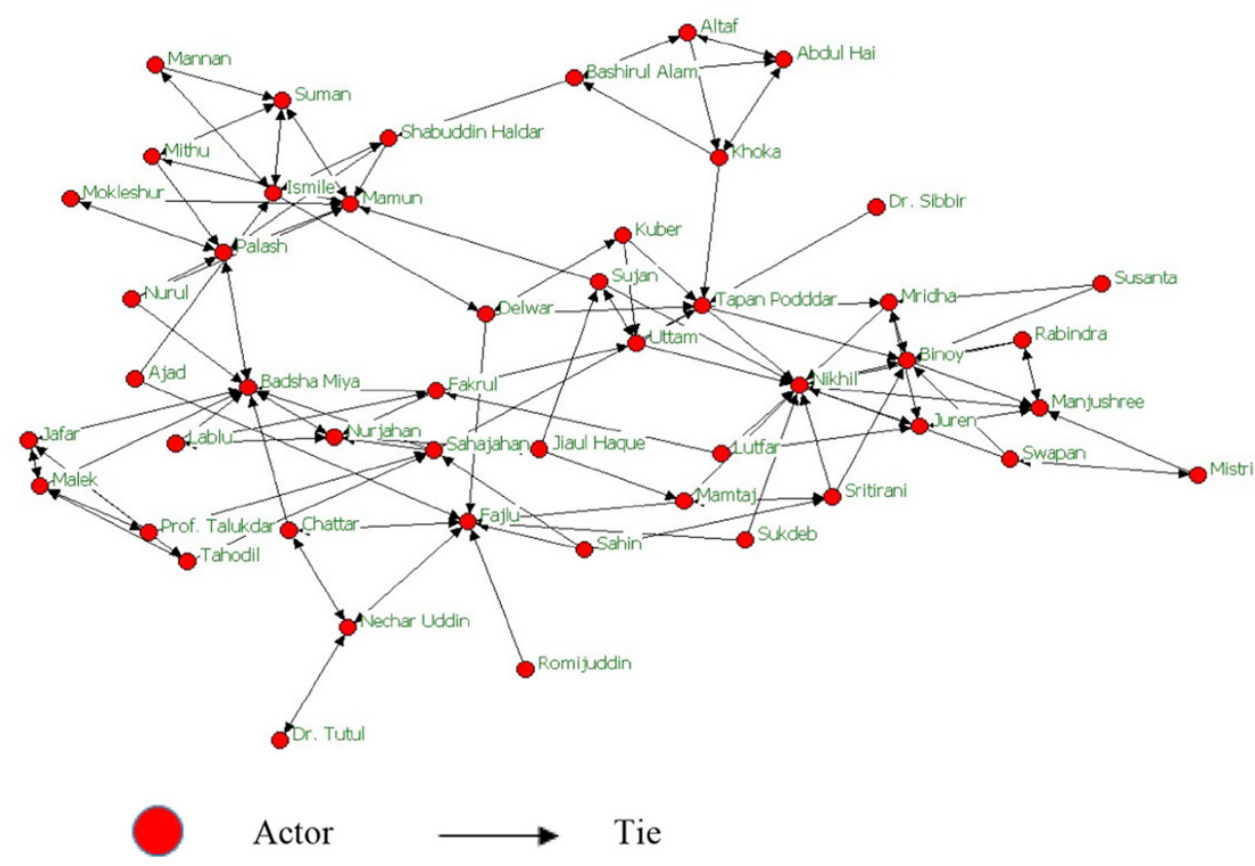

mentioned above. See Fig. 7 for a detailed description of cohesive groups in Morrelganj.

(3) The E-I (external-internal) index technique was used to examine the degree of homogeneity of information sharing and the adopters' group affiliation. The E-I index, as formulated by Krackhardt and Stern (1988), measures the ratios between external ties (between different groups) and internal ties (within groups) and normalizes them to a value with a range of -1.0 to +1.0 . The E-I index is the number of ties external to the groups minus the number of ties that are internal to the group divided by the total number of ties. An E-I index of -1.0 would indicate that only internal relationships exist, while all relationships would be external for an E-I index of +1.0. The E-I index provides not only a measure for the boundaryspanning character of intergroup networks, but also can be used as an indicator of the identity of the network members, that is, their internal or external orientation. Note that there is no optimum value of the E-I index. The desirable relation between internal and external links is always dependent on the circumstances of a specific situation. Since this measure is concerned with any connection between members, the directions of ties are ignored (either an out-tie or an in-tie constitutes a tie between two actors). We used a computer program of UCINET to measure such index.

(4) We used Quadratic Assignment Procedure (QAP), a multi regression technique, provided by UCINET Social Network Software 6.0 Version 1.00 (Borgatti et al. 2002) to find out the actors' social referents for each kind of information-seeking activities. This approach is similar to ordinary multiple regression. However, it enables analysis of matrix data. The equation used was $\mathrm{Y}=\mathrm{B} 0+\mathrm{B} 1$ (Cohesion) $+\mathrm{B} 2$ (Structural Equivalence) + B3 (Neighborhood) + B4 (Religion) + B5 (Income) + B6 (Occupation).

\section{Results}

Rainwater tanks were installed in 8 neighborhoods or Paras of Morrelganj. Table 1 shows that rainwater tank adopters are homogeneous in terms of socioeconomic characteristics, and they are a broadly affluent section of the municipality. The average monthly income of the adopters is 17,776 Taka (USD 180) and a significant number of the households have more than 20,000 Taka (USD 200) monthly income, whereas $40 \%$ of the population of the municipality lives below the national poverty line of USD 2 per day (Morrelaganj Municipality 2002). Residents of the municipality are mainly engaged in agricultural activities, but the tank adopters work in non-agricultural sector as school teachers, college teachers, business people, doctors, pharmacist, and so on. Interestingly, a large number of adopters are school and college teachers. All adopters are literate and a high proportion of them are highly educated, whereas the literacy rate of the municipality is only $70 \%$. One important finding is that though the municipality's population is numerically 
Table 1 Distribution of adopters according to their socioeconomic characteristics

\begin{tabular}{|c|c|}
\hline & $(\%)$ \\
\hline \multicolumn{2}{|l|}{ Religion } \\
\hline Hindu & 30.6 \\
\hline Muslims & 69.4 \\
\hline \multicolumn{2}{|l|}{ Family type } \\
\hline Nuclear & 63.3 \\
\hline Joint & 36.7 \\
\hline \multicolumn{2}{|l|}{ Household size } \\
\hline Up to 2 members & 8.2 \\
\hline 3-4 members & 34.6 \\
\hline 5-6 members & 40.8 \\
\hline 7 or more members & 14.2 \\
\hline \multicolumn{2}{|l|}{ Education } \\
\hline Junior high school & 6.1 \\
\hline High school & 34.7 \\
\hline College & 42.9 \\
\hline Post-graduate & 16.3 \\
\hline \multicolumn{2}{|c|}{ Period of staying in Morrelganj } \\
\hline From birth & 28.6 \\
\hline $30-40$ years & 18.3 \\
\hline 20-29 years & 20.2 \\
\hline $10-19$ years & 18.3 \\
\hline 10 years or less & 14.3 \\
\hline \multicolumn{2}{|l|}{ Income } \\
\hline 10,000 Taka (USD100) & 32.5 \\
\hline 20,000 Taka (USD 200) & 42.8 \\
\hline 30,000 Taka (USD 300) & 16.3 \\
\hline 40,000 Taka (USD 400) & 8.2 \\
\hline \multicolumn{2}{|l|}{ Occupation } \\
\hline School teacher & 36.7 \\
\hline Business people & 24.5 \\
\hline College teacher & 8.2 \\
\hline Government service & 19.3 \\
\hline Agriculture & 4.3 \\
\hline
\end{tabular}

dominated by the Muslims (82\%), a good number of adopters are Hindus. The nature of information and role of social network in the rainwater tank dissemination process are discussed in the next subsection.

\subsection{Information Sharing and Social Networks}

Among the 49 tank adopters, only five (10\%) heard and observed the rainwater tank from the newspaper or TV prior to their adoption. The adopters mainly learned about the tank from interpersonal networks that included friends, neighbors, relatives, and change agents (NGO workers).

Figure 8 shows that the involvement of NGO workers and outsiders is quite high in the hearing process. In other words, a significant number of adopters heard about the rainwater tank from NGO workers or from individuals originating from outside the municipality. However, apart from NGO workers and outsiders, dense hearing networks can be observed among the adopters in Morrelganj. These adopters are not passive recipients of information-once they had adopted the tank, they passed information to others. In the case under discussion, adopters preferred to discuss mainly within the community members rather than discussing with outsiders of the municipality or with the NGO workers (Fig. 10). Significantly, adoption of a tank by one household becomes a source of observation for others (Fig. 9).

Table 2 (also Figs. 8, 9, and 10) indicates that the majority of the adopters heard about the innovation from three persons or more prior to their tank installation, whereas a significant number of adopters observed only one or two tanks before making their decision for adoption. Six of the individuals did not even observe a tank prior to deciding on adoption. Similarly, most of the individuals discussed the tank with only one or two individuals and some of the adopters did not discuss with anyone at all.

\subsection{Social Referents of Information Sharing}

E-I index (Table 3) shows that many information-sharing activities took place outside the economic groups. Adopters received and forwarded all types of information, more with contacts outside their occupational and income groups than within those groups. For example, businessmen exchanged information more with individuals who are not involved in the business sector. In contrast, adopters shared all types of information more within their religious groups. Hindus preferred to share information with other Hindus and the Muslims preferred to share information with fellow Muslims. Similarly, adopters shared all types of information more within their neighborhoods than outside their neighborhoods. However, the E-I index score of neighborhoods in case of observation is lower than hearing and discussion activities. This demonstrates that adopters strongly preferred hearing and discussing within the neighborhood rather than observing. Hearing and discussion also took place more with structural and cohesive group members, rather than outside these groups, whereas observation took place most frequently across structural and cohesive group boundaries.

The QAP multiple regression analysis result displayed in Table 4 shows that adopters heard about the rainwater tank mostly from the cohesive group members. That is, interaction occurred with people with whom the adopters had a higher degree of interaction in day-to-day life. Neighbors are also significant sources for hearing, whereas the adopter's structural equivalent group is not significant. 
Fig. 6 Structurally equivalent group patterns of tank adopters in Morrelganj $(n=49)$. Color indicates the group affiliation of actors. The number of structurally equivalent groups is 8 ; sizes of groups are $4,8,8,2$, $3,4,10$, and 10 . The figure is not drawn to scale. Location of the nodes (actors) are random
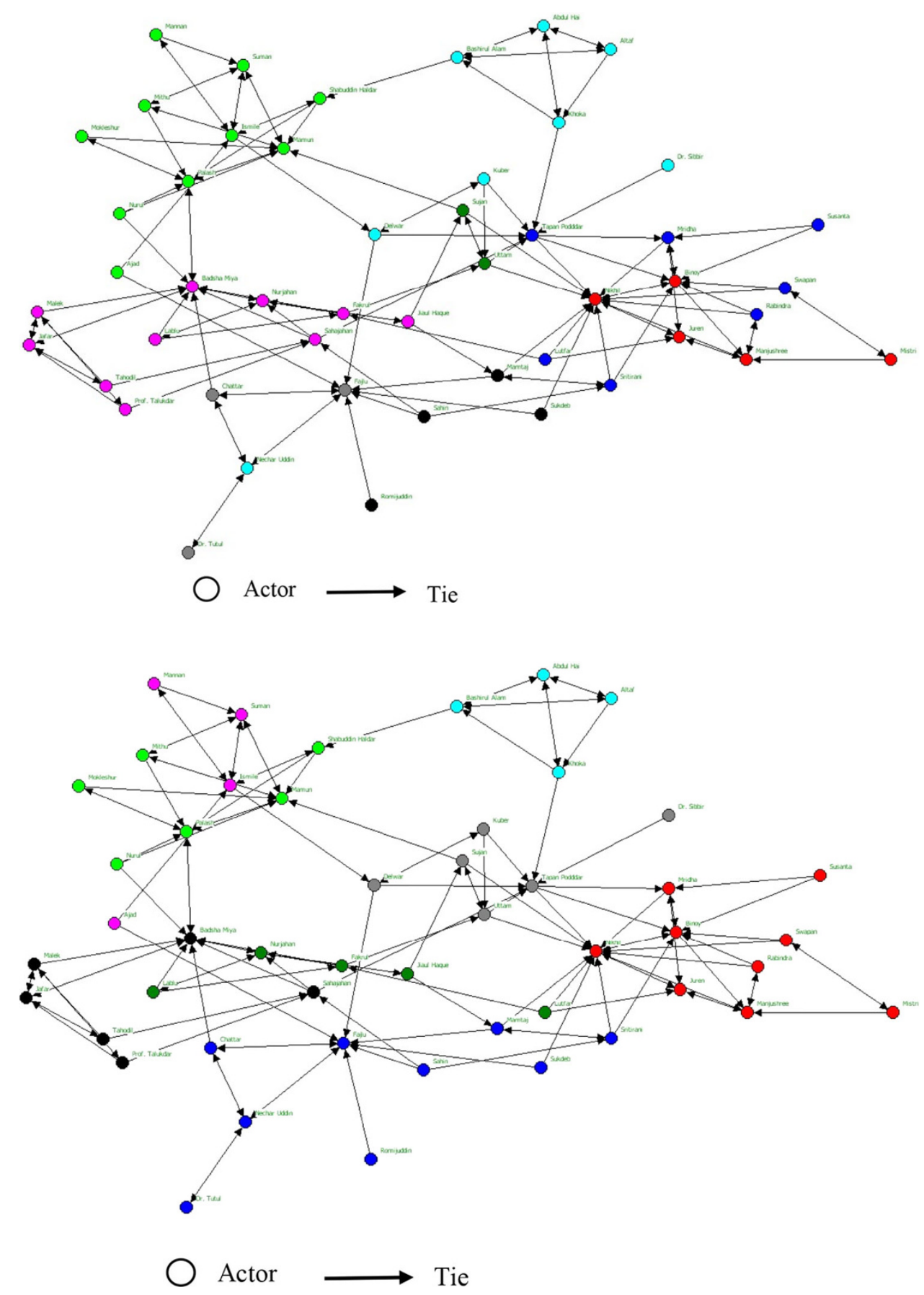

Fig. 7 Cohesive group patterns of tank adopters in Morrelganj $(n=49)$. Color indicates the group affiliation of actors. The number of cohesive groups is 8 ; sizes of groups are 4, 4, 6, 6, 5, 5,9 , and 9 . The figure is not drawn to scale. Location of the nodes (actors) are random
Cultural and economic group partners did not play any significant role for hearing. Observation networks show that adopters observe both their neighbors and cohesive group partners, but neighbors still are the greatest source of observation. Structural equivalence members became more insignificant in this case. Adopters discussed more often with their cohesive group partners than any other group members. Neighbors are also significant as discussion partners, but not the structural equivalent partners or other demographic group members like income, occupational, or religious group members.

\section{Discussion}

To get a comprehensive understanding of the social implementation of rainwater harvesting innovation, this study examines the role of various social networks 
Fig. 8 Social networks of hearing in Morrelganj $(n=49$; total number of actors including outsiders and NGO

workers $=60$ ). Survey

Question: "Kindly name three persons from whom you first heard about the rainwater tank."

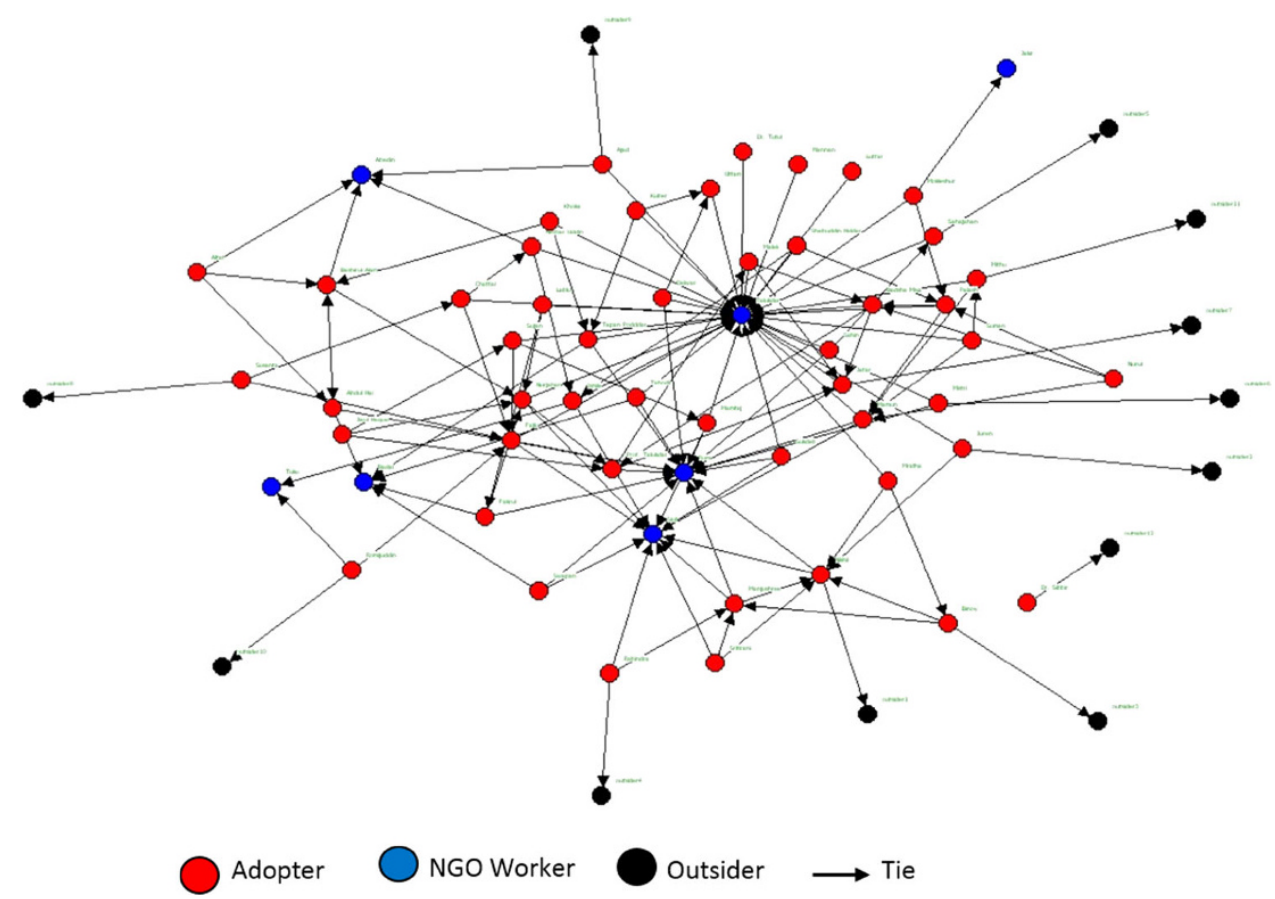

Fig. 9 Social networks of observation in Morrelganj ( $n=49$; total number of actors including outsiders and NGO workers $=60$ ). Survey Question: "Can you remember where you first observed the rainwater tank? If yes, kindly name three places or houses of tank owners where you first observed the rainwater tank."

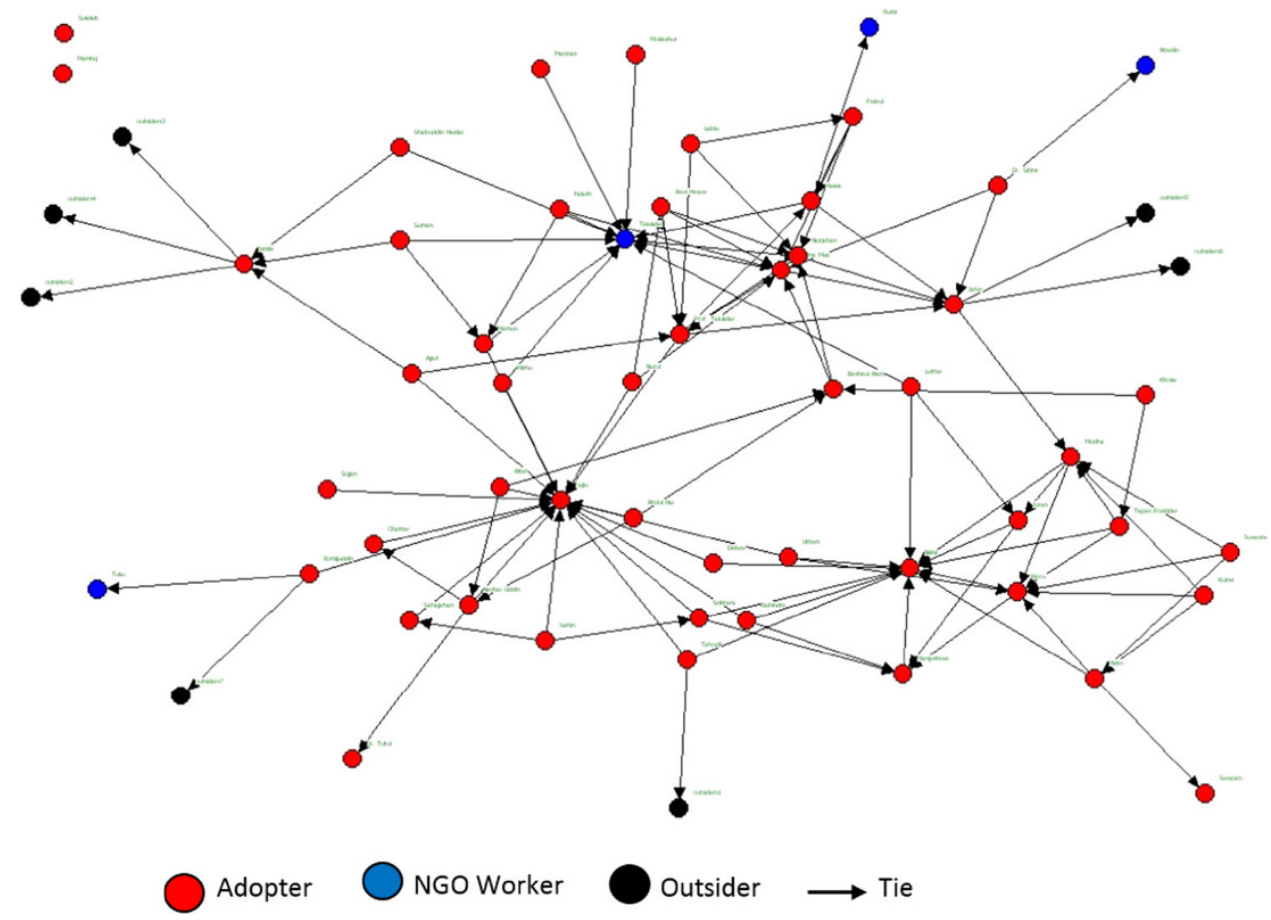

including cohesive groups (friends), structural equivalent groups (individuals who have the same position in society), and spatial groups (neighbors) in three information sharing and processing activities-hearing, observation, and discussion. Our important findings are as follows.

Cohesive groups, that is, individuals who share intimate and strong direct mutual relations, become hearing and discussion partners for rainwater tank adoption, as shown by the QAP analyses (Table 4). The more frequently two individuals communicate, the more likely they are to share and discuss innovative disaster prevention plans. Similar results have been found in risk management studies by Muter et al. (2013) and Scherer and Cho (2003), but their findings are more on risk perception.

Observation is significantly related to geographical proximity and connection (Tables 3,4). Observing other 
people's tanks may not necessarily need social intimacy, but requires physical or geographical proximity, which neighborhood proximity easily provides. It is not necessary that observation partners become hearing or discussion partners. Mere observation may offer an individual the opportunity to visually examine the structure and comprehend the function of the tank or innovation without any further interpretation or data support. Tanks located in popular or public places often become a source of observation and visual examination for a potential adopter without being involved in any verbal and personal interaction with the tank owners.

Structural equivalent groups are not important social referents of information for adopters (Table 4). Therefore a significant conclusion is that competition or a similar social environment does not influence rainwater tank dissemination activities. Tank adopters may prefer to receive information or forward the information only to closely linked individuals.

An interesting finding is that neighbors are significant social referents for adopters in all information seeking activities (Tables 3,4). The reason is that in a majority of

Table 2 Number of sources for acquiring various information (including NGO workers and outsiders)

\begin{tabular}{lrcc}
\hline Number of sources & Hearing & Observation & Discussion \\
\hline From 3 persons & 43 & 29 & 8 \\
From 2 persons & 1 & 8 & 19 \\
From 1 person & 5 & 6 & 13 \\
None & 0 & 6 & 9 \\
Total & 49 & 49 & 49 \\
\hline
\end{tabular}

the cases neighbors are the adopters' cohesive group partners, and people interact most often with their neighbors in daily life irrespective of their religion, occupation, and income. Each neighborhood has unique characteristics and is comprised of a homogeneous group of individuals. Such socioeconomic proximity strengthens social interpersonal contacts and information sharing activities.

Our results show that all types of information-sharing activities were not confined within specific economic groups, that is, groups of individuals having similar occupations or income (Tables 3, 4). Economic group members are not the adopters' social referents with respect to acquiring information. Adopters of tanks are already affluent or members of an elite section of Morrelganj, therefore they are already a segregated group or class set apart from the community. In this already segregated group/class, little economic difference was evident that might have influenced their social interaction patterns and information-sharing activities. Similarly, results show that

Table 3 Sharing various information and degree of homogeneity (EI index value)

\begin{tabular}{llrcc}
\hline Group criteria & & Hearing & Observation & Discussion \\
\hline $\begin{array}{l}\text { Cultural } \\
\text { group }\end{array}$ & Religion & -0.725 & -0.750 & -0.704 \\
$\begin{array}{l}\text { Economic } \\
\text { group }\end{array}$ & Income & 0.333 & 0.364 & 0.333 \\
Spatial group & Occupation & 0.294 & 0.432 & 0.184 \\
Socighborhood & -0.294 & -0.114 & -0.333 \\
$\quad$ network & Cohesive & -0.176 & 0.182 & -0.111 \\
group & Structurally & -0.294 & 0.114 & -0.259 \\
\hline
\end{tabular}

Fig. 10 Social networks of discussion in Morrelganj ( $n=49$; total number of actors including outsiders and NGO workers $=58$ ). Survey Question: "Kindly name three persons with whom you discussed or from whom you took suggestion, advice before your tank installation."

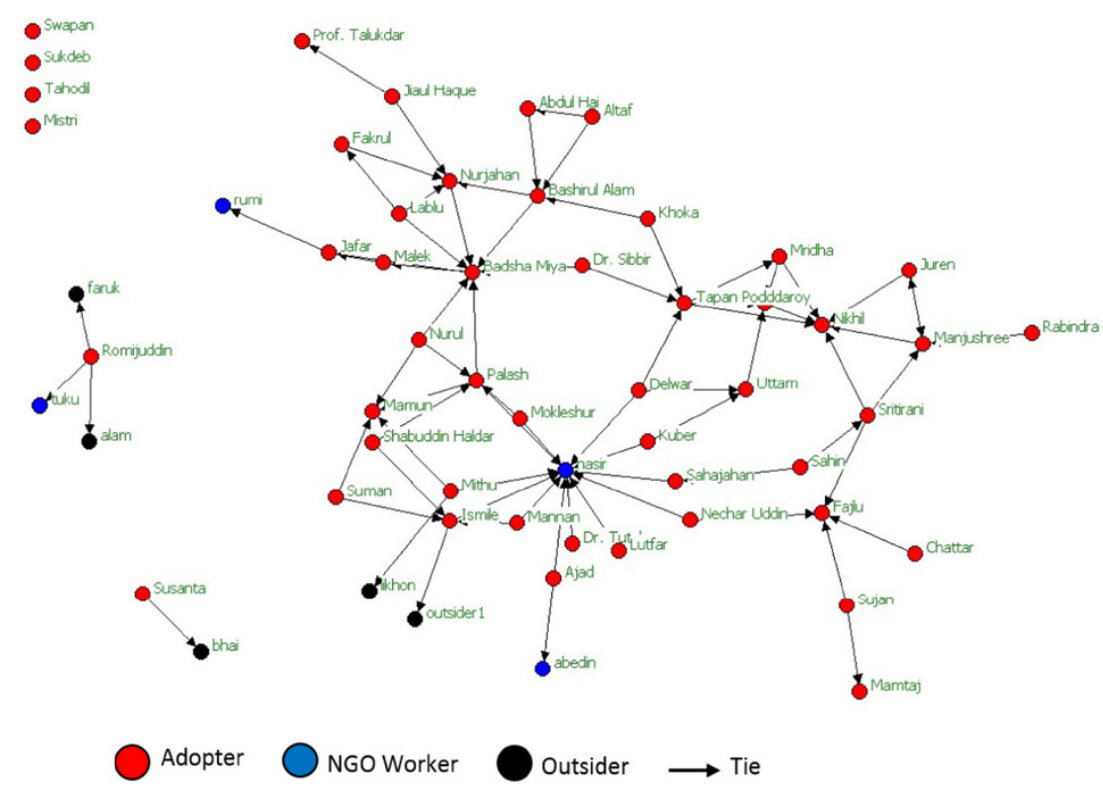


Table 4 Results of regression analysis on social referents for hearing, observation, and discussion

\begin{tabular}{llclc}
\hline Group Criteria & & Hearing & Observation & Discussion \\
\hline Cultural group & Religion & -0.002 & 0.020 & 0.002 \\
Economic group & Income & 0.001 & 0.001 & -0.001 \\
& Occupation & 0.013 & 0.012 & 0.021 \\
Spatial group & Neighborhood & $0.048^{*}$ & $0.090^{* *}$ & $0.061^{*}$ \\
Social network group & Cohesive & $0.080^{* *}$ & $0.072^{* *}$ & $0.081^{* *}$ \\
& Structurally equivalent & 0.027 & 0.001 & 0.018 \\
$R$-Square & & 0.084 & 0.070 & 0.088 \\
\hline
\end{tabular}

$* * p<0.01, * p<0.05$

despite stronger ties within religious groupings, individuals still exchange information across religious boundaries (Tables 3, 4). Social ties often cross the boundaries of religion, economic group, and physical distance. A cohesive group is composed of individuals who have intense social relations irrespective of their cultural and economic background. Higher degrees of social interaction or social ties provide a platform for sharing different information including that related to rainwater harvesting. Hence, during awareness campaigns carried out by NGO workers canvassing door to door to promote rainwater tanks, the involvement of NGO workers in hearing networks is very high, particularly at the initial phase of the dissemination. But over time potential adopters developed more subjective opinions about the advantages and disadvantages of the rainwater tanks from those with whom they are most intimate and directly connected to in their daily life. Therefore the role of NGO workers substantially decreased from hearing to discussion. Because discussion demands a higher degree of trust and confidence between two partners, NGO partners failed to continue as important discussion partners as evaluation of the pros and cons of adoption was exercised amongst the individuals who share and enjoy a common cohesive group membership. Similarly, the role of media and multimedia such as newspapers, TV, and DVD was negligible in this tank dissemination process. The most interesting finding of this study is the vital role of social networks in acquiring necessary information for making adoption decisions, an insight that rarely appears in the disaster and climate change risk management literature.

\section{Conclusions}

Rainwater harvesting technology dissemination is instrumental for reducing drinking water risks in coastal Bangladesh, but the widespread adoption of this preventive measure remains elusive. By focusing on the role of various social networks in the rainwater harvesting adoption process, future studies will uncover a better understanding of the social factors and collective concerns influencing adoption rather than only reveal the individual cognitive perspectives for rainwater harvesting technology dissemination. Since this study is based on an extensive field survey, its empirical findings on social networks offer new directions and valuable insights to risk communication studies in other disaster risk contexts. Recent studies that only analyze disaster preparedness intention and behavior from an individual perspective fail to tell us how individuals are influenced by groups, social norms, and social learning that affect personal beliefs. The present study's findings improve understanding of the adoption process by clarifying the types of actors individuals choose as their social referents in a disaster prevention technology dissemination setting. Research on the determinants of the adoption of disaster preventive measures should not be confined to collecting data on individual demographics and cognitive characteristics, but also include information on the respondents' social networks.

The other planning implications that can be drawn from the present study are that individuals learn from and trust their cohesive partners. This suggests that program planners or NGO workers might take advantage of satisfied tank owners to talk to individuals in close group meetings and workshops organized in a neighborhood. The success stories and personal opinion of existing tank adopters could be documented and distributed in brochures, newsletters, or video promotion for potential adopters to accelerate the social contagion of adoption. Potential adopters are affected by cohesive group partners under these groupings; religious, political, and cultural. These groups and organizations then should be involved in the dissemination process like promoting rainwater tanks during cultural and religious festivals and by direct communications with religious gurus and local leaders. Another strategy to convince potential tank adopters would have the satisfied tank adopters share their experiences adopting the innovation. Our results show that individuals share information among cohesive group partners. Therefore, if the tank owners are satisfied with the tank, penetration of the technology happens more smoothly. But, if the pioneers of tank adopters are not satisfied, their experience would restrict adoption within the same cohesive group. A cohesive group helps the diffusion process only within the 
group and it sometimes produces redundant information and restricts new information and knowledge from entering the group. It is the structural equivalent group members who facilitate the diffusion of innovative technology from one group to another (Burt 1987). Individuals generally do not share tank information among structural equivalent group members, and thus the diffusion of rainwater tank knowledge may be a challenge amongst the respective groups. One way to overcome this bottleneck is to use NGO workers to find the opinion leaders in the promotional program. Observation is a method of learning closely linked with geographical proximity and popularity. Therefore, more model tank demonstrations are needed at various public and popular places including schools, religious centers, clubs, and markets. Furthermore, additional information about the tank (such as cost, size, and purpose) should be provided for potential adopters as comprehensive information about the innovation cannot be deduced by merely observing the tank. Since the role of mass media was negligible in Morrelganj Municipality, local NGOs might test advertising through $\mathrm{TV}$ and newspapers to provide basic information about the tanks to potential adopters who have TVs and those with newspaper subscriptions. Moreover, door-to-door campaigns by NGO workers are recommended to accelerate the promotion of rainwater tank adoption.

Acknowledgments The authors thank the two anonymous reviewers and the editors for their comments on earlier drafts of this manuscript.

Open Access This article is distributed under the terms of the Creative Commons Attribution License which permits any use, distribution, and reproduction in any medium, provided the original author(s) and the source are credited.

\section{References}

Ahmed, M.F., S. Ahuja, M. Alauddin, S.J. Hug, J.R. Lloyd, A. Pfaff, T. Pichler, C. Saltikov, M. Stute, and A. Van Geen. 2006. Ensuring safe drinking water in Bangladesh. Science 314(5806): $1687-1688$.

Akmam, W., and Y. Higano. 2007. Supplying safe water in Bangladesh: A policy model based on multi-objective mixed integer programming. Regional Science 86(1): 57-75.

Alam, M.G.M., G. Allinson, F. Stagnitti, A. Tanaka, and M. Westbrooke. 2002. Arsenic contamination in Bangladesh groundwater: A major environmental and social disaster. International Journal of Environmental Health Research 12(3): 235-253.

Allison, M.A., S.R. Khan, S.L. Goodbred Jr, and S.A. Kuehl. 2003. Stratigraphic evolution of the late Holocene Ganges-Brahmaputra lower delta plain. Sedimentary Geology 155(3): 317-342.

Anawar, H.M., J. Akai, K.M.G. Mostofa, S. Safiullah, and S.M. Tareq. 2002. Arsenic poisoning in groundwater: Health risk and geochemical sources in Bangladesh. Environment International 27(7): 597-604.
Becker, M.H. 1970. Sociometric location and innovativeness: Reformulation and extension of the diffusion model. American Sociological Review 35(2): 267-282.

Behrman, J.R., H.P. Kohler, and S.C. Watkins. 2002. Social networks and changes in contraceptive use over time: Evidence from a longitudinal study in rural Kenya. Demography 39(4): 713-738.

Borgatti, S.P., and M.G. Everett. 1997. Network analysis of 2-mode data. Social Networks 19(3): 243-269.

Borgatti, S.P., M.G. Everett, and L.C. Freeman. 2002. Ucinet for Windows: Software for social network analysis. Analytic Technologies, Harvard, USA. http://pages.uoregon.edu/vburris/ hc431/Ucinet_Guide.pdf. Accessed 24 Apr 2014.

Brenkert-Smith, H., K.L. Dickinson, P.A. Champ, and N. Flores. 2013. Social amplification of wildfire risk: The role of social interactions and information sources. Risk Analysis 33(5): 800-817.

Burt, S.R. 1987. Social contagination and innovation: Cohesion versus structural equivalence. American Journal of Sociology 92(6): 1287-1335.

Coleman, J., E. Katz, and S.H. Menzel. 1957. The diffusion of an innovation among physicians. Sociometry 20(4): 253-270.

Dean, J.W., and D.J. Brass. 1985. Social interaction and the perception of job characteristics in an organization. Human Relations 38(6): 571-582.

Duval, S.T., and J.P. Mulilis. 1999. A person-relative-to-event (PrE) approach to negative threat appeals and earthquake preparedness: A field Study. Journal of Applied Social Psychology 29(3): 495-516.

Gayen, K., and R. Raeside. 2010. Social networks and contraception practice of women in rural Bangladesh. Social Science \& Medicine 71(9): 1584-1592.

Glover, F. 1989. Tabu search-part I. ORSA Journal on Computing 1(3): 190-206.

Granovetter, M. 1978. Threshold models of collective behavior. American Journal of Sociology 83(6): 1420-1443.

Granovetter, M. 1983. The strength of weak ties: A network theory revisited. Sociological Theory 1(1): 201-233.

Grothmann, T., and F. Reusswig. 2006. People at risk of flooding: Why some residents take precautionary action while others do not. Natural Hazards 38(1): 101-120.

Hadi, A. 2003. Fighting arsenic at the grassroots: Experience of BRAC's community awareness initiative in Bangladesh. Health Policy and Planning 18(1): 93-100.

Haque, S.A. 2006. Salinity problems and crop production in coastal regions of Bangladesh. Pakistan Journal of Botany 38(5): $1359-1365$.

Hopenhayn-Rich, C., M.L. Biggs, and A.H. Smith. 1998. Lung and kidney cancer mortality associated with arsenic in drinking water in Cordoba, Argentina. International Journal of Epidemiology 27(4): 561-569.

Hoque, B.A., M.M. Hoque, T. Ahmed, S. Islam, A.K. Azad, N. Ali, M. Hossain, and M.S. Hossain. 2004. Demand-based water options for arsenic mitigation: An experience from rural Bangladesh. Public Health 118(1): 70-77.

Ibarra, H., and S.B. Andrews. 1993. Power, social influence, and sense making: Effects of network centrality and proximity on employee perceptions. Administrative Science Quarterly 38(2): 277-303.

Integrated Regional Information Networks. 2007. Bangladesh: Rising sea levels threaten agriculture. IRIN humanitarian News and Analysis. http://www.irinnews.org/report/75094/bangladesh-ris ing-sea-levels-threaten-agriculture. Accessed 24 Apr 2014.

Jakariya, M., A.M.R. Chowdhury, Z. Hossain, M. Rahman, Q. Sarker, R.I. Khan, and M. Rahman. 2003. Sustainable community-based safe water options to mitigate the Bangladesh arsenic catastrophe-An experience from two upazilas. Current Science 85(2): 141-146. 
Karim, M.D. 2000. Arsenic in groundwater and health problems in Bangladesh. Water Research 34(1): 304-310.

Katz, E. 1957. The two-step flow of communication: An up-to-date report on a hypothesis. Public Opinion Quarterly 21(1): 61-78.

Khan, N.I., and H. Yang. 2013. Arsenic mitigation in Bangladesh: An analysis of institutional stakeholders' opinions. Science of the Total Environment. http://dx.doi.org/10.1016/j.scitotenv.2013. 11.007. Accessed 24 Apr 2014.

Khan, A.E., A. Ireson, S. Kovats, S.K. Mojumder, A. Khusru, A. Rahman, and P. Vineis. 2011. Drinking water salinity and maternal health in coastal Bangladesh: Implications of climate change. Environmental Health Perspectives 119(9): 1328-1332.

Krackhardt, D., and R.N. Stern. 1988. Informal networks and organizational crises: An experimental simulation. Social Psychology Quarterly 51(2): 123-140.

Lin, N., and R.S. Burt. 1975. Differential effects of information channels in the process of innovation diffusion. Social Forces 54(1): 256-274.

Lindell, M.K., and D.J. Whitney. 2000. Correlates of household seismic hazard adjustment adoption. Risk Analysis 20(1): 13-26.

Marsden, P.V., and N.E. Friedkin. 1994. Network studies of social influence. In Advances in social network analysis: Research in the social and behavioral sciences, ed. S. Wasserman, and J. Galaskiewicz, 3-25. Thousand Oaks: Sage.

Martin, I.M., H. Bender, and C. Raish. 2007. What motivates individuals to protect themselves from risks: The case of wildland fires. Risk Analysis 27(4): 887-900.

Menzel, H., and E. Katz. 1955. Social relations and innovation in the medical profession: The epidemiology of a new drug. Public Opinion Quarterly 19(4): 337-352.

MOEF (Ministry of Environment and Forest), Bangladesh. 2006. Impact of sea-level rise on land use suitability and adaptation options: Coastal land zoning in the southwest. Dhaka: Ministry of Environment and Forest.

Morrelganj Municipality. 2002. Morrelganj municipality survey report. Morrelganj, Bangladesh (in Bengali).

Morrelganj Upazila Karjalay (Morrelganj Sub-District Council). 2003. Bangladesh arsenic mitigation water supply project, Morrelganj. Morrelganj, Bangladesh (in Bengali).

Mosler, H.J., O.R. Blöchliger, and J. Inauen. 2010. Personal, social, and situational factors influencing the consumption of drinking water from arsenic-safe deep tubewells in Bangladesh. Journal of Environmental Management 91(6): 1316-1323.

Muter, B.A., M.L. Gore, and S.J. Riley. 2013. Social contagion of risk perceptions in environmental management networks. Risk Analysis 33(8): 1489-1499.

Paton, D. 2008. Risk communication and natural hazard mitigation: How trust influences its effectiveness. International Journal of Global Environmental Issues 8(1): 2-16.
Paton, D., G. Kelly, P.T. Burgelt, and M. Doherty. 2006. Preparing for bushfires: Understanding intentions. Disaster Prevention and Management 15(4): 566-575.

Rogers, M.E. 1983. Diffusion of innovations. New York: Free Press.

Samaddar, S., and N. Okada. 2007. Reducing drinking water pollution risks through implementing rainwater harvesting-An analysis of social innovation. In Proceeding of the SRA-JAPAN annual conference, 255-260. Japan: Society for Risk Analysis.

Samaddar, S., and N. Okada. 2008. Modelling and analysis of rainwater harvesting technology disseminating process based on social networks threshold approach. In 2008 IEEE international conference on Systems, man, and cybernetics (SMC), 2494-2501.

Samaddar, S., B.A. Misra, R. Chatterjee, and H. Tatano. 2012. Understanding community's evacuation intention development process in a flood prone micro-hotspot, Mumbai. IDRiM Journal 2(2): 1-19.

Sarwar, M.G.M. 2005. Impacts of sea level rise on the coastal zone of Bangladesh. Lund, Sweden: Lund University International Masters Programme in Environmental Science, Lund University. http://static.weadapt.org/placemarks/files/225/golam_sarwar.pdf. Accessed 24 Apr 2014.

Scherer, C.W., and H. Cho. 2003. A social network contagion theory of risk perception. Risk Analysis 23(2): 261-267.

School of Environmental Studies, Jadavpur University, India. 2004. Groundwater arsenic contamination in Bangladesh (10 years study). http://www.soesju.org/arsenic/bangladesh.htm. Accessed 24 Apr 2014.

Schramm, W. 1973. Men, messages, and media: A look at human communication. New York: Harper \& Row.

Shah, P.P. 1998. Who are employees' social referents? Using a network perspective to determine referent others. Academy of Management Journal 41(3): 249-268.

Smith, A.H., E.O. Lingas, and M. Rahman. 2000. Contamination of drinking-water by arsenic in Bangladesh: A public health emergency. Bulletin of the World Health Organization 78(9): 1093-1103.

Tekeli-Yeşil, S., N. Dedeoğlu, C. Braun-Fahrlaender, and M. Tanner. 2010. Factors motivating individuals to take precautionary action for an expected earthquake in Istanbul. Risk Analysis 30(8): $1181-1195$.

Terpstra, T. 2011. Emotions, trust, and perceived risk: Affective and cognitive routes to flood preparedness behavior. Risk Analysis 31(10): 1658-1675.

Valente, T.W. 1995. Network models of the diffusion of innovations. Cresskill: Hampton Press.

Valente, T.W. 1996. Social network thresholds in the diffusion of innovations. Social Networks 18(1): 69-89. 